\title{
ANALISIS HUBUNGAN MOTIVASI DAN PRESTASI BELAJAR DALAM MATA PELAJARAN (IPS) TERPADU
}

\author{
Sulastri \\ SMAN 2 Lubuk Sikaping Kabupaten Pasaman Timur \\ sulastriiskandar@gmail.com
}

\begin{abstract}
ABSTRAK
Penelitian ini bertujuan untuk mengetahui hubungan antara motivasi belajar siswa dengan prestasi belajar siswa. Peneliti melihat beberapa permasalahan tentang motivasi belajar, yang mana siswa-siswi kelas 8 di SMPN 2 Kec. Situjuah Limo Nagari kurang termotivasi dalam belajar pada mata pelajaran IPS Terpadu dan berimbas pada prestasi belajar seperti nilai Latihan, Pr, Ujian harian, Ujian tengah semester, dan Ujian akhir semester. Jenis penelitian yang digunakan adalah penelitian kuantitatif dengan pendekatan korelasi. Adapun teknik pengumpulan data yang digunakan peneliti diantaranya observasi dan angket. Hasil penelitian menunjukkan bahwa berdasarkan keseluruhan item soal di dapat 3,31. Ini berarti bahwa motivasi belajar siswa berada dalam kualifikasi baik sebagaimana semestinya yang di harapkan. Dari hasil uji hipotesis dan pengolahan data terdapat hubungan antara motivasi belajar siswa dan prestasi belajar siswa sehingga di peroleh harga koefisien antara $\mathrm{x}$ dan y sebesar 0,56 berarti dalam kategori sedang. Maka dapat diartikan bahwa motivasi belajar siswa kelas 8 di SMPN 2 Kec. Situjuah Limo Nagari dalam tingkatan baik dalam menunjang kegiatan pembelajaran pada mata pelajaran (IPS) Terpadu sehingga mempengaruhi prestasi belajar. "Terdapat hubungan signifikan antara motivasi belajar siswa dengan prestasi belajar pada mata pelajaran (IPS) Terpadu pada kelas 8 di SMPN $2 \mathrm{Kec}$. Situjuan Limo Nagari Tahun Ajaran 2018/2019 “ Diterima ini berarti terdapat hubungan antara motivasi belajar dengan prestasi belajar siswa di SMPN 2 Kec.Situjuah Limo Nagari. Dari hasil penelitian dapat disimpulkan bahwa motivasi belajar siswa adalah baik dan memiliki hubungan anatara motivasi belajar dengan prestasi siswa.
\end{abstract}

Kata Kunci : Motivasi Belajar, Prestasi belajar

\begin{abstract}
This study aims to determine the relationship between student motivation and student achievement. The researcher looked at several problems regarding learning motivation, in which 8th grade students at SMPN 2 Kec. Situjuah Limo Nagari is less motivated in learning on Integrated Social Sciences subjects and impacts on learning achievements such as Exercise scores, Pr, Daily Exams, Midterm Exams, and Final semester Exams. The type of research used is quantitative research with a correlation approach. The data collection techniques used by researchers include observation and questionnaires. The results of the study showed that based on the overall items of the questions obtained 3.31 This
\end{abstract}


means that students' learning motivation is in good qualifications as expected. From the results of hypothesis testing and data processing there is a relationship between student learning motivation and student learning achievement so that the price coefficient obtained between $x$ and $y$ is 0.56 means in the medium category. Then it can be interpreted that the learning motivation of the 8th grade students at SMPN 2 Kec. Situjuah Limo Nagari is in a good level in supporting learning activities on the subject (IPS) Integrated so that it affects learning achievement. "There is a significant relationship between student learning motivation and learning achievement on Integrated (IPS) subjects at grade 8 at SMPN 2 Kec. Si Limo Nagari Academic Year 2018/2019" Accepted this means that there is a relationship between learning motivation and student achievement at SMPN 2 Kec. Situjuah Limo Nagari. From the results of this study concluded that student motivation is good and has a relationship between learning motivation and student achievement

Keyword : Motivation Learning, Achievement Learning

\section{PENDAHULUAN}

Motivasi belajar merupakan salah satu faktor yang turut menentukan keaktifan dalam pembelajaran. Seorang peserta didik akan belajar dengan baik apabila ada faktor pendorongnya yaitu motivasi belajar. Peserta didik akan belajar dengan sungguh-sungguh jika memiliki motivasi belajar yang tinggi. Motivasi belajar adalah seluruh daya penggerak di dalam diri siswa yang menimbulkan kegiatan belajar yang menjamin kelangsungan dari kegiatan belajar yang memberikan arah pada kegiatan belajar sehingga tujuan yang di kehendaki oleh subjek belajar itu dapat dicapai (Sardiman A.M, 2007)

Ada banyak faktor yang mempengaruhi motivasi belajar yang dapat di bedakan menjadi dua faktor. Motivasi belajar dapat di timbulkan karena faktor internal dan eksternal.

Faktor internal yang mempengaruhi motivasi belajar yaitu : faktor fisik meliputi nutrisi (Gizi),Kesehatan, dan fungsi-fungsi fisik (Terutama panca indra). Faktor psikologis, yaitu berhubungan dengan aspek-aspek yang mendorong atau menghambat aktivitas belajar siswa.
Faktor eksternal (berasal dari lingkungan) yang mempengaruhi motivasi belajar meliputi: Faktor non sosial meliputi udara (cuaca panas atau dingin), dan waktu (pagi, siang, dan alam), Tempat (sepi, bising, atau kualitas sekolah, tempat belajar), suasana dan prasarana atau fasilitas belajar. Faktor sosial, merupakan faktor manusia (guru, konselor, dan orang tua).

Berdasarkan faktor internal dan eksternal yang di kemukakan di atas,sikap siswa termasuk faktor internal motivasi belajar yaitu psikologis. Sikap siswa ini merupakan hasil yang ditunjukkan siswa terhadap cara mengajar guru dan penggunaan alat bantu pembelajaran.

Faktor lain yang mempengaruhi motivasi belajar siswa adalah cara mengajar guru. Dengan artian bahwa kalau seorang guru hanya menggunakan metode ceramah makan akan membuat suasana belajar akan menjadi membosakan dan akan membuat motivasi belajar siswa menurun.

Prestasi belajar merupakan hasil pengukuran terhadap peserta didik setelah mengikuti proses pembelajaran 
dalam periode tertentu yang dapat diukur menggunakan instrumen yang relevan. Banyak faktor yang mempengaruhi prestasi belajar, ada yang dari dalam diri (internal) dan ada yang dari luar diri (eksternal). Faktor eksternal yang berasal dari luar diri siswa berupa faktor sosial, budaya, lingkungan fisik, dan lingkungan spritual keagamaan. Faktor sosial meliputi lingkungan keluarga, sekolah, dan masyarakat. Faktor budaya meliputi adat istiadat, ilmu pengetahuan, teknologi, dan kesenian. Faktor lingkungan fisik seperti fasilitas rumah dan fasilitas belajar. Fasilitas belajar meliputi ruang belajar, meja, kursi, penerangan, alat tulis, dan buku-buku pelajaran. Faktor tersebut saling berinteraksi baik secara langsung maupun tidak langsung dalam mempengaruhi prestasi belajar.

Jika siswa mempunyai fasilitas belajar yang lengkap, maka tugas dari guru dapat dikerjakan daengan baik. Jadi apabila siswa mendapatkan fasilitas belajar yang baik dan diukung oleh kemampuan siswa dalam memanfaatkannya secara optimal diharapkan dapat meningkatkan prestasi belajar siswa.Syaiful Bahri Djamarah, (2008).

Salah satu indikator pendidikan berkualitas adalah perolehan hasil belajar yang maksimal oleh siswa, baik itu hasil belajar dalam bentuk kognitif, afektif maupun psikomotor. Hasil belajar siswa sangat dipengaruhi oleh kegiatan proses belajar mengajar yang didalamnya terdapat beberap faktor yang merupakan penentu lancar atau tidaknya kegiatan proses belajar mengajar. Instrumen Input yaitu; kurikulum, perpustakaan, guru dan sebagainya. Raw input yaitu ; siswa, motivasi, cara belajar dan sebagainya. Environmental input yaitu ; lingkungan fisik dan sosial budaya.
Dari ketiga faktor utama yang mempengaruhi lancar tidaknya proses pembelajaran tersebut di atas, dalam penelitian ini difokuskan pada usaha siswa meningkatkan motivasi belajarnya untuk mendapatkan prestasi belajar yang baik dan memuaskan yang sekaligus akan berpengaruh pada peningkatan kualitas sumber daya manusia (Agustina, 2011).

Dalam proses belajar mengajar, motivasi merupakan salah satu faktor yang diduga besar pengaruhnya terhadap hasil belajar. Siswa yang motivasinya tinggi diduga akan memperoleh hasil belajar yang baik. Pentingnya motivasi belajar siswa terbentuk antara lain agar terjadi perubahan belajar ke arah yang lebih positif (Syaiful Bahri Djamarah, 2008).

Begitu pula halnya bila kita lihat dalam proses belajar mengajar sejarah. Siswa yang memiliki motivasi yang tinggi dalam mempelajari sejarah akan melakukan kegiatan lebih cepat dibandingkan dengan siswa yang kurang termotivasi dalam mempelajari sejarah. Siswa yang yang memiliki motivasi yang tinggi dalam mempelajari sejarah maka prestasi yang diraih juga akan lebih baik.

Sehubungan dengan faktorfaktor tersebut, guru sangat berperan dalam meningkatkan motivasi belajar. Karena dari hasil pengamatan penulis dari bertanya langsung dari muridmurid SMPN 2 Kec.Situjuah Limo Nagari Bahwasanya belajar (IPS) Sejarah sangat lah membosankan. Semua itu mungkin di pengaruhidari cara penyampaian materi dari guru dan metode pembelajaran yang tidak di variatif kan serta hanya terfokus dengan LKS saja.

Dari sana penulis sudah bisa mengambil kesimpulan bahwa siswa kelas VII SMPN 2 Kec.Situjuah Limo 
Nagari kurang termotivasi dalam mata pelajaran (IPS) Sejarah dan akan berimbas pada prestasi belajar mata pelajaran tersebut. Oleh karena itu, guru harus mampu mencipatakan pembelajaran yang menarik dan menyenangkan agar siswa memiliki motivasi belajar yang tinggi. Agar siswa termotivasi dan merasa senang dalam mengikuti pembelajaran maka, sangat diperlukan keterampilanketerampilan guru dalam mengajar sesuai dengan perkembangan zaman dan kemajuan teknologi.

\section{METODE PENELITIAN}

Jenis Penelitian yang digunakan dalam penelitian ini adalah penelitian kuantitatif dengan pendekatan korelasi. Menurut Sugiyono, (2010) Penelitian kuantitatif adalah metode penelitian yang berlandaskan pada filsafat positivisme, digunakan untuk meneliti pada populasi atau sampel tertentu.

Teknik pengambilan sampel pada umumnya dilakukan secara random, Pengumpulan data menggunakan instrumen penelitian. Analisis bersifat kuantitatif/statistik. Selain itu metode penelitian kuantitatif dikatakan sebagai metode yang lebih simple pada aspek pengukuran secara objektif terhadap fenomenan sosial.

Untuk dapat melakukan pengukuran, Setiap fenomena sosial dijabarkan kedalam beberapa komponen masalah. Variabel dan indikator. Sedangkan pendekatan korelasi adalah mencari hubungan dua variabel. Dalam penelitianini variabelnya adalah hubungan motivasi dan prestasi siswa.

\section{HASIL DAN PEMBAHASAN Data Hasil Angket Motivasi siswa}

Berikut diuraikan data dari hasil skor angket motivasi siswa sebagai berikut:

Tabel 1 Saya memperhatikan dengan sungguh-sungguh materi yang di sampaikan oleh guru

\begin{tabular}{|c|c|c|c|c|c|}
\hline $\begin{array}{l}\mathrm{N} \\
\mathrm{O}\end{array}$ & $\begin{array}{l}\text { Alternatif } \\
\text { jawaban }\end{array}$ & $\begin{array}{l}\text { Jumlah } \\
\text { Siswa }\end{array}$ & Skor & $\begin{array}{l}\text { Perse } \\
\text { ntase }\end{array}$ & Mean \\
\hline 1 & Selalu & 8 & 32 & $\begin{array}{l}32 \\
\%\end{array}$ & \\
\hline 2 & Sering & 14 & 42 & $\begin{array}{l}56 \\
\%\end{array}$ & 3,32 \\
\hline 3 & $\begin{array}{l}\text { Kadang- } \\
\text { kadang }\end{array}$ & 3 & 9 & $\begin{array}{l}12 \\
\%\end{array}$ & \\
\hline 4 & $\begin{array}{l}\text { Tidak } \\
\text { pernah }\end{array}$ & & & & \\
\hline \multicolumn{2}{|c|}{ Jumlah } & 25 & 83 & 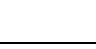 & \\
\hline
\end{tabular}

Dari tabel di atas diketahui bahwa banyak siswa yang menjawab selalu (8) sering (14), kadang-kadang (3), Tidak Pernah (0). Analisa pada angketSaya memperhatikan dengan sungguh-sungguh materi yang di sampaikan oleh guru di dapat rata-rata skor $(3,32)$ artinya berada pada kategori sangat baik.

2) Saya bersemangat mengerjakan tugas yang diberikan guru

Tabel 2 Saya bersemangat mengerjakan tugas yang diberikan guru

\begin{tabular}{llllll}
\hline $\begin{array}{l}\text { No. } \\
\text { Alternatif } \\
\text { jawaban }\end{array}$ & $\begin{array}{l}\text { Jumlah } \\
\text { Siswa }\end{array}$ & Skor & $\begin{array}{l}\text { Persent } \\
\text { ase }\end{array}$ & $\begin{array}{l}\sum(X) \\
\text { Rata- } \\
\text { rata }\end{array}$ \\
\hline 1 & Selalu & 7 & 28 & $28 \%$ & \\
2 & Sering & 14 & 42 & $56 \%$ & \\
3 & $\begin{array}{l}\text { Kadang- } \\
\text { kadang }\end{array}$ & 3 & 6 & $12 \%$ & \\
4 & $\begin{array}{l}\text { Tidak } \\
\text { pernah }\end{array}$ & 1 & 1 & $4 \%$ & \\
& & & & \\
\hline Jumlah & 25 & 77 & & 3,08 \\
\hline Rata-rata & & & & \\
\hline &
\end{tabular}


Dari tabel di atas diketahui bahwa banyak siswa yang menjawab selalu (7) sering (14), kadang-kadang (3), dan tidak pernah (1). Analisa pada angketSaya bersemangat mengerjakan tugas yang diberikan guru didapat rata-rata skor $(3,08)$ artinya berada pada kategori baik.

3) Saya senang mendapatkan pujian ketika mendapat nilai bagus

Tabel 3Saya senang mendapatkan pujian ketika mendapat nilai bagus

\begin{tabular}{|c|c|c|c|c|c|}
\hline No. & $\begin{array}{l}\text { Alternatif } \\
\text { jawaban }\end{array}$ & $\begin{array}{l}\text { Jumlah } \\
\text { Siswa }\end{array}$ & $\begin{array}{l}\text { Sk } \\
\text { or }\end{array}$ & $\begin{array}{l}\text { Perse } \\
\text { ntase }\end{array}$ & $\begin{array}{l}\sum(X) \\
\text { Rata- } \\
\text { rata }\end{array}$ \\
\hline 1 & Selalu & 16 & 64 & $\begin{array}{l}64 \\
\%\end{array}$ & \\
\hline 2 & Sering & 4 & 12 & $\begin{array}{l}16 \\
\%\end{array}$ & \\
\hline 3 & $\begin{array}{l}\text { Kadang- } \\
\text { kadang }\end{array}$ & 3 & 6 & $\begin{array}{l}12 \\
\%\end{array}$ & \\
\hline 4 & $\begin{array}{l}\text { Tidak } \\
\text { pernah }\end{array}$ & 2 & 2 & $8 \%$ & \\
\hline \multicolumn{2}{|c|}{ Jumlah } & 25 & 84 & & \\
\hline \multicolumn{2}{|c|}{ Rata-rata } & & & & 3,36 \\
\hline
\end{tabular}

Dari tabel di atas diketahui bahwa banyak siswa yang menjawab selalu (16), sering (4), kadang-kadang (3), tidak pernah (2). Analisa pada angket Saya senang mendapatkan pujian ketika mendapat nilai bagus didapat rata-rata skor $(3,36)$ artinya berada pada kategori sangat baik.

4) Saya masuk kelas sebelum bel berbunyi

Tabel 4 Saya masuk kelas sebelum bel berbunyi

\begin{tabular}{|c|c|c|c|c|c|}
\hline \multicolumn{6}{|c|}{ berbunyi } \\
\hline $\mathrm{N}$ & Alternatif & Jumlah & $\mathrm{Sk}$ & Perse & $\sum(X) \mathrm{R}$ \\
\hline o. & jawaban & Siswa & or & ntase & ata-rata \\
\hline 1 & Selalu & 16 & 64 & 64 & \\
\hline & & & & $\%$ & \\
\hline 2 & Sering & 4 & 12 & 16 & \\
\hline & & & & $\%$ & \\
\hline 3 & Kadang- & 3 & 6 & 12 & \\
\hline & kadang & & & $\%$ & \\
\hline 4 & $\begin{array}{l}\text { Tidak } \\
\text { pernah }\end{array}$ & 2 & 2 & $8 \%$ & \\
\hline & nlah & 25 & 84 & & \\
\hline & a-rata & & & & 3,36 \\
\hline
\end{tabular}

Dari tabel di atas diketahui bahwa banyak siswa yang menjawab selalu (16), sering (4), kadang-kadang (3), tidak pernah (2). Analisa pada angketSaya masuk kelas sebelum bel berbunyi didapat rata-rata skor $(3,36)$ artinya berada pada kategori sangat baik.

Tabel 5 Saya berusaha tepat waktu mengumpulkan latihan dan pekerjaan rumah

\begin{tabular}{|c|c|c|c|c|c|}
\hline $\begin{array}{l}\mathrm{N} \\
\mathrm{o} .\end{array}$ & $\begin{array}{l}\text { Alternatif } \\
\text { jawaban }\end{array}$ & $\begin{array}{l}\text { Jumlah } \\
\text { Siswa }\end{array}$ & Skor & $\begin{array}{l}\text { Per } \\
\text { sent } \\
\text { ase }\end{array}$ & $\begin{array}{l}\sum(X) \\
\text { Rata- } \\
\text { rata }\end{array}$ \\
\hline 1 & Selalu & 12 & 48 & $\begin{array}{l}48 \\
\%\end{array}$ & \\
\hline 2 & Sering & 8 & 24 & $\begin{array}{l}32 \\
\%\end{array}$ & \\
\hline 3 & $\begin{array}{l}\text { Kadang- } \\
\text { kadang }\end{array}$ & 4 & 8 & $\begin{array}{l}16 \\
\%\end{array}$ & \\
\hline 4 & $\begin{array}{l}\text { Tidak } \\
\text { pernah }\end{array}$ & 1 & 1 & $\begin{array}{l}4 \\
\% \\
\end{array}$ & \\
\hline \multicolumn{2}{|c|}{ Jumlah } & 25 & 81 & & \\
\hline \multicolumn{2}{|c|}{ Rata-rata } & & & & 3,24 \\
\hline
\end{tabular}

Sumber : Pengolahan data sekunder 2018

Dari tabel di atas diketahui bahwa banyak siswa yang menjawab selalu (12) sering (24), kadang-kadang (8), tidak pernah (1) .Analisa pada angket Saya berusaha tepat waktu mengumpulkan latihan dan pekerjaan rumahdidapat rata-rata skor $(3,24)$ artinya berada pada kategori baik

Tabel 6 Memanfaatkan waktu yang ada untuk menyelesaiakan tugas dan latihan yang diberikan

\begin{tabular}{llllll}
\hline $\mathrm{N}$ & $\begin{array}{l}\text { Alternatif } \\
\text { jawaban }\end{array}$ & $\begin{array}{l}\text { Jumlah } \\
\text { Siswa }\end{array}$ & $\begin{array}{l}\text { Sko } \\
\mathrm{r}\end{array}$ & $\begin{array}{l}\text { Pers } \\
\text { entas } \\
\text { e }\end{array}$ & $\begin{array}{l}\sum(X) \\
\text { Rata } \\
\text {-rata }\end{array}$ \\
\hline 1 & Selalu & 11 & 44 & $\begin{array}{l}44 \\
\%\end{array}$ & \\
2 & Sering & 10 & 30 & $\begin{array}{l}40 \\
\%\end{array}$ & \\
3 & $\begin{array}{l}\text { Kadang- } \\
\text { kadang } \\
\text { Tidak } \\
\text { pernah }\end{array}$ & 2 & 4 & $8 \%$ & \\
4 & 2 & 2 & $8 \%$ & \\
\hline
\end{tabular}

\begin{tabular}{|c|c|c|}
\hline Jumlah & 25 & 80 \\
\hline
\end{tabular}


Dari tabel di atas diketahui bahwa banyak siswa yang menjawab selalu (11), sering (10), kadangkadang (2), dan tidak pernah (2). Analisa pada angket Memanfaatkan waktu yang ada untuk menyelesaiakan tugas dan latihan yang diberikandidapat rata-rata skor $(3,2)$ artinya berada pada kategori baik.

Tabel 7Sarapan sebelum berangkat ke sekolah

\begin{tabular}{llllll}
\hline $\begin{array}{l}\text { N } \\
\text { o. }\end{array}$ & $\begin{array}{l}\text { Alternatif } \\
\text { jawaban }\end{array}$ & $\begin{array}{l}\text { Jumla } \\
\text { h } \\
\text { Siswa }\end{array}$ & $\begin{array}{l}\text { S } \\
\text { ko }\end{array}$ & $\begin{array}{l}\text { Pers } \\
\text { entas }\end{array}$ & $\begin{array}{l}\sum(X) \\
\text { Rata- } \\
\text { rata }\end{array}$ \\
\cline { 1 - 3 } 1 & Selalu & 6 & 24 & $\begin{array}{l}24 \\
\%\end{array}$ & \\
& & & & & \\
2 & Sering & 2 & 6 & $8 \%$ & \\
3 & Kadang- & 14 & 28 & 56 & \\
& kadang & & & $\%$ & \\
4 & Tidak & 3 & 3 & 12 & \\
& pernah & & & &
\end{tabular}

Jumlah $\quad 25 \quad 61$

Rata-rata $25 \quad 61$

Sumber : Pengolahan data sekunder 2018

Dari tabel di atas diketahui bahwa banyak siswa yang menjawab selalu (6) sering (2), kadang-kadang (14), dan tidak pernah (3). Analisa pada angket Sarapan sebelum berangkat ke sekolah didapat rata-rata skor $(2,44)$ artinya berada pada kategori kurang baik.

Tabel 8Membawa bekal untuk menghemat uang jajan agar bisa menabung

\begin{tabular}{|c|c|c|c|c|c|}
\hline No & $\begin{array}{l}\text { Alternati } \\
\mathrm{f} \\
\text { jawaban }\end{array}$ & $\begin{array}{l}\text { Jumlah } \\
\text { Siswa }\end{array}$ & $\begin{array}{l}\mathrm{S} \\
\text { ko } \\
\mathrm{r}\end{array}$ & $\begin{array}{l}\text { Pers } \\
\text { entas } \\
\mathrm{e}\end{array}$ & $\begin{array}{l}\sum(X) \\
\text { Rata- } \\
\text { rata }\end{array}$ \\
\hline 1 & Selalu & 3 & 12 & $\begin{array}{l}12 \\
\%\end{array}$ & \\
\hline 2 & Sering & 1 & 3 & $4 \%$ & \\
\hline 3 & $\begin{array}{l}\text { Kadang- } \\
\text { kadang }\end{array}$ & 10 & 20 & $\begin{array}{l}40 \\
\%\end{array}$ & \\
\hline 4 & $\begin{array}{l}\text { Tidak } \\
\text { pernah }\end{array}$ & 11 & 11 & $\begin{array}{l}44 \\
\%\end{array}$ & \\
\hline
\end{tabular}

\begin{tabular}{lcc}
\hline Jumlah & 25 & 46 \\
\hline Rata-rata & & 1,84 \\
\hline \multicolumn{2}{l}{ Sumber : Pengolahan data sekunder } & 2018
\end{tabular}

Dari tabel di atas diketahui bahwa banyak siswa yang menjawab selalu(3) sering (1), kadang-kadang (10), dan tidak pernah (11). Analisa pada angketMembawa bekal untuk menghemat uang jajan agar bisa menabungdidapat rata-rata skor $(1,84)$ artinya berada pada kategori kurang baik.

Tabel 9Ketika jam istirahat saya selalu makan dan minum secukupnya

\begin{tabular}{llllll}
\hline $\begin{array}{l}\text { N } \\
\text { o. }\end{array}$ & $\begin{array}{l}\text { Alternati } \\
\text { f } \\
\text { jawaban }\end{array}$ & $\begin{array}{l}\text { Jumlah } \\
\text { Siswa }\end{array}$ & $\begin{array}{l}\text { Sko } \\
\text { r }\end{array}$ & $\begin{array}{l}\text { Pers } \\
\text { entas } \\
\text { e }\end{array}$ & $\begin{array}{l}\sum(X) \\
\text { Rata- } \\
\text { rata }\end{array}$ \\
\hline 1 & Selalu & 15 & 60 & $\begin{array}{l}60 \\
\%\end{array}$ & \\
2 & Sering & 5 & 40 & $\begin{array}{l}20 \\
\%\end{array}$ & \\
3 & $\begin{array}{l}\text { Kadang- } \\
\text { kadang } \\
\text { Tidak } \\
\text { pernah }\end{array}$ & 3 & 6 & $\begin{array}{l}12 \\
\%\end{array}$ & \\
& 2 & 2 & $8 \%$ & \\
\hline
\end{tabular}

\begin{tabular}{lcc}
\hline Jumlah & 25 & 108 \\
\hline Rata-rata & 4,32 \\
\hline Sumber : Pengolahan data sekunder 2018
\end{tabular}

Dari tabel di atas diketahui bahwa banyak siswa yang menjawab selalu (15) sering (5), kadang-kadang (3), tidak pernah (2). Analisa pada angketKetika jam istirahat saya selalu makan dan minum secukupnya didapat rata-rata skor $(4,32)$ artinya berada pada kategori sangat baik.

Tabel 10Lebih mudah memahami materi jika dihubungkan dengan kehidupan sehari2

$\mathrm{N}$ Alternatif Jumlah Sko Pers $\sum(X)$

o jawaban Siswa $r$ entas Rata-

\begin{tabular}{llllll}
. & & & e & rata \\
\hline 1 & Selalu & 13 & 52 & 52 & \\
$\%$
\end{tabular}

$\begin{array}{lllll}2 & \text { Sering } & 7 & 21 & 28\end{array}$

3 Kadang- $5 \quad 10 \quad 20$

kadang \%

4 Tidak pernah

\begin{tabular}{lcr}
\hline Jumlah & 25 & 83 \\
\hline Rata-rata & & 3,32 \\
\hline \multicolumn{3}{l}{ Sumber : Pengolahan data sekunder 2018 }
\end{tabular}

Dari tabel di atas diketahui bahwa banyak siswa yang menjawab 
selalu (13) sering (7), kadang-kadang (5), dan tidak pernah (0). Analisa pada angketLebih mudah memahami materi jika dihubungkan dengan kehidupan sehari-hari didapat rata-rata skor $(3,32)$ artinya berada pada kategori sangat baik.

Tabel 11Saya merasa bosan jika guru selalu berceramah dan menyuruh mengisi LKS (-)

\begin{tabular}{|c|c|c|c|c|c|}
\hline $\begin{array}{l}\text { No } \\
\text {. }\end{array}$ & $\begin{array}{l}\text { Alternati } \\
\mathrm{f} \\
\text { jawaban }\end{array}$ & $\begin{array}{l}\text { Jumlah } \\
\text { Siswa }\end{array}$ & $\begin{array}{l}\mathrm{S} \\
\text { ko } \\
\mathrm{r}\end{array}$ & $\begin{array}{l}\text { Pers } \\
\text { entas } \\
\mathrm{e}\end{array}$ & $\begin{array}{l}\sum(X) \\
\text { Rata- } \\
\text { rata }\end{array}$ \\
\hline 1 & Selalu & 8 & 32 & $\begin{array}{l}32 \\
\%\end{array}$ & \\
\hline 2 & Sering & 7 & 21 & $\begin{array}{l}28 \\
\%\end{array}$ & \\
\hline 3 & $\begin{array}{l}\text { Kadang- } \\
\text { kadang }\end{array}$ & 7 & 14 & $\begin{array}{l}28 \\
\%\end{array}$ & \\
\hline 4 & $\begin{array}{l}\text { Tidak } \\
\text { pernah }\end{array}$ & 3 & 3 & $\begin{array}{l}12 \\
\%\end{array}$ & \\
\hline
\end{tabular}

\begin{tabular}{lrrr}
\hline Jumlah & 25 & 70 & \\
\hline Rata-rata & & & 2,80 \\
\hline
\end{tabular}

Sumber : Pengolahan data sekunder 2018

Dari tabel di atas diketahui bahwa banyak siswa yang menjawab selalu (8) sering (7), kadang-kadang (7), tidak pernah (3). Analisa pada angketSaya merasa bosan jika guru selalu berceramah dan menyuruh mengisi LKS didapat rata-rata skor $(2,8)$ artinya berada pada kategori baik.

Tabel 12Saya senang jika penyampaian materi menggunakan media

\begin{tabular}{llllll}
\hline $\begin{array}{l}\mathrm{N} \\
\text { o. }\end{array}$ & $\begin{array}{l}\text { Alternati } \\
\text { jawaban }\end{array}$ & $\begin{array}{l}\text { Jumlah } \\
\text { Siswa }\end{array}$ & $\begin{array}{l}\text { S } \\
\text { ko } \\
\text { r }\end{array}$ & $\begin{array}{l}\text { Pers } \\
\text { entas }\end{array}$ & $\begin{array}{l}\sum(X) \\
\text { Rata- } \\
\text { rata }\end{array}$ \\
\hline 1 & Selalu & 10 & 40 & $\begin{array}{l}40 \\
\%\end{array}$ & \\
2 & Sering & 10 & 30 & $\begin{array}{l}40 \\
\%\end{array}$ & \\
3 & $\begin{array}{l}\text { Kadang- } \\
\text { kadang } \\
\text { Tidak } \\
\text { pernah }\end{array}$ & 3 & 6 & $\begin{array}{l}12 \\
\%\end{array}$ & \\
& 2 & 2 & $8 \%$ & \\
\hline Jumlah & 25 & 78 & & 3,12 \\
\hline Rata-rata & & & & \\
\hline
\end{tabular}

Dari tabel di atas diketahui bahwa banyak siswa yang menjawab selalu (10) sering (10), kadang-kadang
(3), dan tidak pernah (2) Analisa pada angketSaya senang jika penyampaian materi menggunakan media didapat rata-rata skor $(3,2)$ artinya berada pada kategori baik.

Tabel 13Saya lebih suka mencatat daripada mendengarkan apa yang disampaikan guru (-)

\begin{tabular}{|c|c|c|c|c|c|}
\hline $\begin{array}{l}\mathrm{N} \\
\mathrm{O} \\
.\end{array}$ & $\begin{array}{l}\text { Alternatif } \\
\text { jawaban }\end{array}$ & $\begin{array}{l}\text { Jumlah } \\
\text { Siswa }\end{array}$ & $\begin{array}{l}\text { Sko } \\
\mathrm{r}\end{array}$ & $\begin{array}{l}\text { Pers } \\
\text { entas } \\
\text { e }\end{array}$ & $\begin{array}{l}\sum(X) \\
\text { Rata- } \\
\text { rata }\end{array}$ \\
\hline 1 & Selalu & 2 & 8 & $8 \%$ & \\
\hline 2 & Sering & 8 & 24 & $\begin{array}{l}32 \\
\%\end{array}$ & \\
\hline 3 & $\begin{array}{l}\text { Kadang- } \\
\text { kadang }\end{array}$ & 9 & 18 & $\begin{array}{l}36 \\
\%\end{array}$ & \\
\hline 4 & $\begin{array}{l}\text { Tidak } \\
\text { pernah }\end{array}$ & 6 & 6 & $\begin{array}{l}24 \\
\%\end{array}$ & \\
\hline
\end{tabular}

\begin{tabular}{lll}
\hline Jumlah & 25 & 56 \\
\hline Rata-rata & 2,24 \\
\hline \multicolumn{3}{l}{ Sumber. Pengolahan data sekunder 2018}
\end{tabular}

Dari tabel di atas diketahui bahwa banyak siswa yang menjawab selalu (2) sering (8), kadang-kadang (9), dan tidak pernah (6). Analisa pada angketSaya lebih suka mencatat daripada mendengarkan apa yang disampaikan guru didapat rata-rata skor $(2,24)$ artinya berada pada kategori kurang baik.

Tabel 14Saya senang berdikusi dengan teman tentang apa yang sudah dipelajari

\begin{tabular}{llllll}
\hline $\begin{array}{l}\mathrm{N} \\
\mathrm{o}\end{array}$ & $\begin{array}{l}\text { Alternatif } \\
\text { jawaban }\end{array}$ & $\begin{array}{l}\text { Jumlah } \\
\text { Siswa }\end{array}$ & $\begin{array}{l}\text { Sko } \\
\mathrm{r}\end{array}$ & $\begin{array}{l}\text { Pers } \\
\text { entas } \\
\mathrm{e}\end{array}$ & $\begin{array}{l}\sum(X) \\
\text { Rata- } \\
\text { rata }\end{array}$ \\
\hline 1 & Selalu & 10 & 40 & $\begin{array}{l}40 \\
\%\end{array}$ & \\
2 & Sering & 10 & 30 & $\begin{array}{l}40 \\
\%\end{array}$ & \\
3 & Kadang- & 5 & 10 & $\begin{array}{l}20 \\
\%\end{array}$ & \\
& kadang & & & & \\
\hline $\begin{array}{l}\text { Tidak } \\
\text { pernah }\end{array}$ & & & & & \\
\hline Jumlah & 25 & 80 & & \\
\hline \multicolumn{2}{l}{ Rata-rata } & & & & 3,20 \\
\hline
\end{tabular}

Sumber : Pengolahan data sekunder 2018

Dari tabel di atas diketahui bahwa banyak siswa yang menjawab selalu (10) sering (10), kadang-kadang (5), dan tidak pernah (0). Analisa pada 
angketSaya senang berdikusi dengan teman tentang apa yang sudah dipelajari didapat rata-rata skor $(3,2)$ artinya berada pada kategori baik.

Tabel 15Belajar bersama dengan teman-teman untuk mengerjakan tugas atau PR yang sulit (-

\begin{tabular}{llllll}
\hline $\begin{array}{l}\mathrm{N} \\
\mathrm{O}\end{array}$ & $\begin{array}{l}\text { Alternatif } \\
\text { jawaban }\end{array}$ & $\begin{array}{l}\text { Jumlah } \\
\text { Siswa }\end{array}$ & $\begin{array}{l}\mathrm{S} \\
\text { ko } \\
\mathrm{r}\end{array}$ & $\begin{array}{l}\text { Pers } \\
\text { entas }\end{array}$ & $\begin{array}{l}\sum(X) \mathrm{R} \\
\text { ata-rata }\end{array}$ \\
\hline 1 & Selalu & 6 & 24 & $\begin{array}{l}24 \\
\%\end{array}$ \\
2 & Sering & 7 & 21 & $\begin{array}{l}28 \\
\%\end{array}$ \\
3 & $\begin{array}{l}\text { Kadang- } \\
\text { kadang } \\
\text { Tidak } \\
\text { pernah }\end{array}$ & 10 & 20 & $\begin{array}{l}40 \\
\%\end{array}$ \\
& 2 & 2 & $8 \%$
\end{tabular}

\begin{tabular}{lcc}
\hline Jumlah & 25 & 67 \\
\hline Rata-rata & & 2,68 \\
\hline Sumber : Pengolahan data sekunder & 2018
\end{tabular}

Dari tabel di atas diketahui bahwa banyak siswa yang menjawab selalu (6) sering (7), kadang-kadang (10), dan tidak pernah (2). Analisa pada angketBelajar bersama dengan teman-teman untuk mengerjakan tugas atau PR yang sulitdidapat rata-rata skor $(2,68)$ artinya berada pada kategorit baik.

Tabel 16Saya senang membantu teman yang kesulitan dalam belajar

\begin{tabular}{llllll}
\hline $\begin{array}{l}\mathrm{N} \\
\mathrm{o}\end{array}$ & $\begin{array}{l}\text { Alternatif } \\
\text { jawaban }\end{array}$ & $\begin{array}{l}\text { Jumlah } \\
\text { Siswa }\end{array}$ & $\begin{array}{l}\text { Sko } \\
\mathrm{r}\end{array}$ & $\begin{array}{l}\text { Persen } \\
\text { tase }\end{array}$ & $\begin{array}{l}\sum(X) \mathrm{R} \\
\text { ata-rata }\end{array}$ \\
\hline 1 & Selalu & 10 & 40 & $40 \%$ & \\
2 & Sering & 8 & 24 & $32 \%$ & \\
3 & $\begin{array}{l}\text { Kadang- } \\
\text { kadang }\end{array}$ & 6 & 12 & $24 \%$ & \\
4 & Tidak & 1 & 1 & $4 \%$ & \\
& pernah & & & &
\end{tabular}

\begin{tabular}{lccc}
\hline Jumlah & 25 & 77 & \\
\hline Rata-rata & & 3,08 \\
\hline
\end{tabular}

Dari tabel di atas diketahui bahwa banyak siswa yang menjawab selalu (10) sering (8), kadang-kadang (6), dan tidak pernah (1). Analisa pada angket Saya senang membantu teman yang kesulitan dalam belajar didapat rata-rata skor $(3,08)$ artinya berada pada kategori baik.

Tabel 17Saya senang jika pekerjaan rumah selalu di koreksi oleh orang tua/saudara.

\begin{tabular}{|c|c|c|c|c|c|}
\hline $\begin{array}{l}\mathrm{N} \\
\mathrm{O} \\
.\end{array}$ & $\begin{array}{l}\text { Alternatif } \\
\text { jawaban }\end{array}$ & $\begin{array}{l}\text { Jumlah } \\
\text { Siswa }\end{array}$ & Skor & $\begin{array}{l}\text { Persen } \\
\text { tase }\end{array}$ & $\begin{array}{l}\sum(X) \\
\text { Rata- } \\
\text { rata }\end{array}$ \\
\hline 1 & Selalu & 4 & 16 & $6 \%$ & \\
\hline 2 & Sering & 9 & 27 & $36 \%$ & \\
\hline 3 & $\begin{array}{l}\text { Kadang- } \\
\text { kadang }\end{array}$ & 7 & 14 & $28 \%$ & \\
\hline 4 & $\begin{array}{l}\text { Tidak } \\
\text { pernah }\end{array}$ & 5 & 5 & $20 \%$ & \\
\hline \multicolumn{2}{|c|}{ Jumlah } & 25 & 62 & & \\
\hline \multicolumn{2}{|c|}{ Rata-rata } & & & & 2.48 \\
\hline
\end{tabular}

Dari tabel di atas diketahui bahwa banyak siswa yang menjawab sering (4), selalu (9), kadang-kadang (7), dan tidak pernah (5). Analisa pada angketSaya senang jika pekerjaan rumah selalu di koreksi oleh orang tua/saudaradidapat rata-rata skor $(2,48)$ artinya berada pada kategori kurang baik.

Tabel 18Saya memilih di antar oleh orang tua/saudara ke sekolah dan jemput ketika pulang sekolah

\begin{tabular}{|c|c|c|c|c|c|}
\hline $\begin{array}{l}\mathrm{N} \\
\mathrm{O}\end{array}$ & $\begin{array}{l}\text { Alternatif } \\
\text { jawaban }\end{array}$ & $\begin{array}{l}\text { Jumlah } \\
\text { Siswa }\end{array}$ & Skor & $\begin{array}{l}\text { Persen } \\
\text { tase }\end{array}$ & $\begin{array}{l}\sum(X) \\
\text { Rata } \\
\text {-rata }\end{array}$ \\
\hline 1 & Selalu & 3 & 12 & $12 \%$ & \\
\hline 2 & Sering & 6 & 18 & $24 \%$ & \\
\hline 3 & $\begin{array}{l}\text { Kadang- } \\
\text { kadang }\end{array}$ & 5 & 10 & $20 \%$ & \\
\hline 4 & $\begin{array}{l}\text { Tidak } \\
\text { pernah }\end{array}$ & 11 & 11 & $44 \%$ & \\
\hline \multicolumn{2}{|c|}{ Jumlah } & 25 & 51 & & \\
\hline \multicolumn{2}{|c|}{ Rata-rata } & & & & 2,04 \\
\hline
\end{tabular}

Dari tabel di atas diketahui bahwa banyak siswa yang menjawab selalu (3) sering (6), kadang-kadang (5), dan tidak pernah (11). Analisa pada angketSaya memilih di antar oleh orang tua/saudara ke sekolah dan jemput ketika pulang sekolah didapat 
rata-rata skor $(2,04)$ artinya berada pada kategori kurang baik.

Tabel 19Pujian dari orang tua/saudara selalu membuat saya bersemanggat

\begin{tabular}{|c|c|c|c|c|c|}
\hline $\begin{array}{l}\mathrm{N} \\
\mathrm{o} .\end{array}$ & $\begin{array}{l}\text { Alternatif } \\
\text { jawaban }\end{array}$ & $\begin{array}{l}\text { Jumlah } \\
\text { Siswa }\end{array}$ & Skor & $\begin{array}{l}\text { Pers } \\
\text { enta } \\
\text { se }\end{array}$ & $\begin{array}{l}\sum(X) \\
\text { Rata } \\
\text {-rata }\end{array}$ \\
\hline 1 & Selalu & 19 & 76 & $\begin{array}{l}76 \\
\%\end{array}$ & \\
\hline 2 & Sering & 2 & 6 & $8 \%$ & \\
\hline 3 & $\begin{array}{l}\text { Kadang- } \\
\text { kadang }\end{array}$ & 2 & 4 & $8 \%$ & \\
\hline 4 & $\begin{array}{l}\text { Tidak } \\
\text { pernah }\end{array}$ & 2 & 4 & $8 \%$ & \\
\hline \multicolumn{2}{|c|}{ Jumlah } & 25 & 90 & & \\
\hline \multicolumn{2}{|c|}{ Rata-rata } & & & & 3,60 \\
\hline
\end{tabular}

Sumber : Pengolahan data sekunder 2018

Dari tabel di atas diketahui bahwa banyak siswa yang menjawab selalu (19), sering (2), kadang-kadang (2), dan tidak pernah (2). Analisa pada angketPujian dari orang tua/saudara selalu membuat saya bersemanggat didapat rata-rata skor $(3,6)$ artinya berada pada kategori sangat baik.

Tabel 20Saya selalu bertanya kepada orang tua/saudara jika ada yang saya tidak mengerti dari pelajaran disekolah dan pekerjaan rumah

\begin{tabular}{|c|c|c|c|c|c|}
\hline $\begin{array}{l}\mathrm{N} \\
\mathrm{o} \\
.\end{array}$ & $\begin{array}{l}\text { Alternatif } \\
\text { jawaban }\end{array}$ & $\begin{array}{l}\text { Jumlah } \\
\text { Siswa }\end{array}$ & $\begin{array}{l}\text { Sko } \\
\text { r }\end{array}$ & $\begin{array}{l}\text { Persen } \\
\text { tase }\end{array}$ & $\begin{array}{l}\sum(X) \\
\text { Rata } \\
\text {-rata }\end{array}$ \\
\hline 1 & Selalu & 11 & 44 & $44 \%$ & \\
\hline 2 & Sering & 8 & 24 & $32 \%$ & \\
\hline 3 & $\begin{array}{l}\text { Kadang- } \\
\text { kadang }\end{array}$ & 5 & 10 & $20 \%$ & \\
\hline 4 & $\begin{array}{l}\text { Tidak } \\
\text { pernah }\end{array}$ & 1 & 1 & $4 \%$ & \\
\hline & nlah & 25 & 79 & & \\
\hline & ta-rata & & & & 3,16 \\
\hline
\end{tabular}

Dari tabel di atas diketahui bahwa banyak siswa yang menjawab selalu (11), seing (8), kadang-kadang (5), dan tidak pernah (1). Analisa pada angketSaya selalu bertanya kepada orang tua/saudara jika ada yang saya tidak mengerti dari pelajaran disekolah dan pekerjaan rumah didapat rata-rata skor $(3,16)$ artinya berada pada kategori baik.

Tabel 21Saya senang mendapatkan nilai tinggi

dalam setiap latihan dan pekerjaan rumah

\begin{tabular}{|c|c|c|c|c|c|}
\hline $\begin{array}{l}\mathrm{N} \\
\mathrm{O}\end{array}$ & $\begin{array}{l}\text { Alternatif } \\
\text { jawaban }\end{array}$ & $\begin{array}{l}\text { Jumlah } \\
\text { Siswa }\end{array}$ & $\begin{array}{l}\text { Sko } \\
\mathrm{r}\end{array}$ & $\begin{array}{l}\text { Persen } \\
\text { tase }\end{array}$ & $\begin{array}{l}(X) \\
\text { Rata- } \\
\text { rata }\end{array}$ \\
\hline 1 & Selalu & 20 & 80 & $80 \%$ & \\
\hline 2 & Sering & 3 & 9 & $12 \%$ & \\
\hline 3 & $\begin{array}{l}\text { Kadang- } \\
\text { kadang }\end{array}$ & 1 & 2 & $4 \%$ & \\
\hline 4 & $\begin{array}{l}\text { Tidak } \\
\text { pernah }\end{array}$ & 1 & 1 & $4 \%$ & \\
\hline \multicolumn{2}{|c|}{ Jumlah } & 25 & 91 & & \\
\hline \multicolumn{2}{|c|}{ Rata-rata } & & & & 3,64 \\
\hline
\end{tabular}

Sumber : Pengolahan data sekunder 2018

Dari tabel di atas diketahui bahwa banyak siswa yang menjawab selalu (20), sering (3), kadang-kadang (1), dan tidak pernah (1). Analisa pada angket Saya senang mendapatkan nilai tinggi dalam setiap latihan dan pekerjaan rumah didapat rata-rata skor $(3,64)$ artinya berada pada kategori sangat baik.

Tabel 22Saya berusaha mendapatkan nilai tinggi

\begin{tabular}{|c|c|c|c|c|c|}
\hline $\begin{array}{l}\mathrm{N} \\
\mathrm{o} \\
.\end{array}$ & $\begin{array}{l}\text { Alternatif } \\
\text { jawaban }\end{array}$ & $\begin{array}{l}\text { Jumlah } \\
\text { Siswa }\end{array}$ & $\begin{array}{l}\text { Sko } \\
\mathrm{r}\end{array}$ & $\begin{array}{l}\text { Persen } \\
\text { tase }\end{array}$ & $\begin{array}{l}\sum(\square) \\
\text { Rata- } \\
\text { rata }\end{array}$ \\
\hline 1 & Selalu & 20 & 80 & $80 \%$ & \\
\hline 2 & Sering & 3 & 9 & $12 \%$ & \\
\hline 3 & $\begin{array}{l}\text { Kadang- } \\
\text { kadang }\end{array}$ & 1 & 2 & $4 \%$ & \\
\hline 4 & $\begin{array}{l}\text { Tidak } \\
\text { pernah }\end{array}$ & 1 & 1 & $4 \%$ & \\
\hline \multicolumn{2}{|c|}{ Jumlah } & 25 & 81 & & \\
\hline \multicolumn{2}{|c|}{ Rata-rata } & & & & 3,64 \\
\hline
\end{tabular}

Dari tabel di atas diketahui bahwa banyak siswa yang menjawab selalu (20), selalu (3) kadang-kadang (1), dan tidak pernah (1). Analisa pada angketSaya berusaha mendapatkan nilai tinggi didapat rata-rata skor $(3,64)$ artinya berada pada kategori sangat baik. 
Tabel 23Tinggi/rendahnya nilai yang saya dapatkan akan selalu saya syukuri

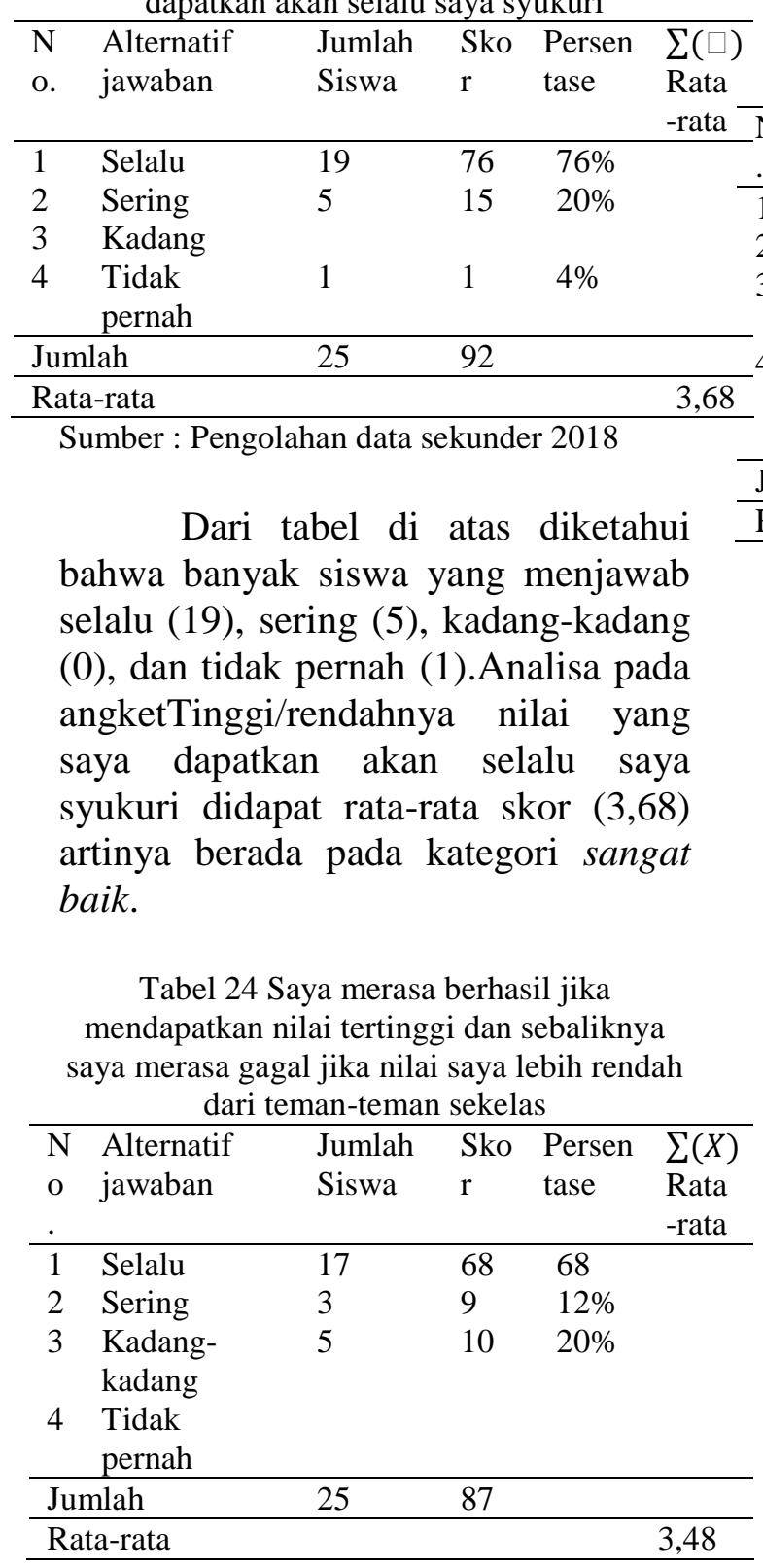

Tabel 25 Saya akan berusaha memahami setiap apa yang sudah di pelajari dan akan

\begin{tabular}{|c|c|c|c|c|c|c|c|c|c|c|c|}
\hline \multirow[t]{2}{*}{ o. } & \multirow[t]{2}{*}{ jawaban } & \multirow[t]{2}{*}{ Siswa } & \multirow[t]{2}{*}{$\mathrm{r}$} & \multirow[t]{2}{*}{ tase } & \multirow{2}{*}{$\begin{array}{l}\text { Rata } \\
\text {-rata }\end{array}$} & \multicolumn{5}{|c|}{ terus mengingatnya } & \multirow{3}{*}{$\begin{array}{l}\sum(X) \mathrm{R} \\
\text { ata-rata }\end{array}$} \\
\hline & & & & & & No & Alternatif & Jumlah & Sko & Persen & \\
\hline 1 & Selalu & 19 & 76 & $76 \%$ & & . & jawaban & Siswa & $\mathrm{r}$ & tase & \\
\hline 2 & Sering & 5 & 15 & $20 \%$ & & 1 & Selalu & 10 & 40 & $40 \%$ & \\
\hline 3 & Kadang & & & & & 2 & Sering & 8 & 24 & $32 \%$ & \\
\hline 4 & $\begin{array}{l}\text { Tidak } \\
\text { pernah }\end{array}$ & 1 & 1 & $4 \%$ & & 3 & $\begin{array}{l}\text { Kadang- } \\
\text { kadang }\end{array}$ & 6 & 12 & $24 \%$ & \\
\hline \multicolumn{2}{|c|}{ Jumlah } & 25 & 92 & & & 4 & Tidak & 1 & 1 & $4 \%$ & \\
\hline \multicolumn{2}{|c|}{ Rata-rata } & & & & 3,68 & & pernah & & & & \\
\hline \multirow{2}{*}{\multicolumn{6}{|c|}{ Sumber : Pengolahan data sekunder 2018}} & & & & & & \\
\hline & & & & & & \multicolumn{2}{|c|}{ Jumlah } & 25 & 77 & & \\
\hline & $\mathrm{D}$ & ibel $\mathrm{d}$ & atas & diket: & & Rat & -rata & & & & 3,08 \\
\hline
\end{tabular}
bahwa banyak siswa yang menjawab Sumber : Pengolahan data sekunder 2018

Dari tabel di atas diketahui bahwa banyak siswa yang menjawab sering (10), selalu (8) kadang-kadang (8), dan tidak pernah (1). Analisa pada angketSaya akan berusaha memahami setiap apa yang sudah di pelajari dan akan terus mengingatnya didapat ratarata skor $(3,08)$ artinya berada pada kategoribaik.

Tabel 26Saya akan mengulang-ulang pelajaran yang sudah agar faham tujuan dari

\begin{tabular}{|c|c|c|c|c|c|}
\hline \multicolumn{6}{|c|}{ pelajaran tersebut } \\
\hline $\mathrm{N}$ & Alternatif & Jumlah & Sko & Persen & $\sum(X)$ \\
\hline $\begin{array}{l}\text { o } \\
.\end{array}$ & jawaban & Siswa & $\mathrm{r}$ & tase & $\begin{array}{l}\text { Rata- } \\
\text { rata }\end{array}$ \\
\hline 1 & Selalu & 7 & 28 & $28 \%$ & \\
\hline 2 & Sering & 13 & 39 & $52 \%$ & \\
\hline 3 & $\begin{array}{l}\text { Kadang- } \\
\text { kadang }\end{array}$ & 4 & 8 & $16 \%$ & \\
\hline 4 & $\begin{array}{l}\text { Tidak } \\
\text { pernah }\end{array}$ & 1 & 1 & $2 \%$ & \\
\hline & mlah & 25 & 76 & & \\
\hline & ta-rata & & & & 3,04 \\
\hline
\end{tabular}

Dari tabel di atas diketahui Sumber : Pengolahan data sekunder 2018 bahwa banyak siswa yang menjawab sering (17), sering (3) kadang-kadang (5), dan tidak pernah (0). Analisa pada angketSaya merasa berhasil jika mendapatkan nilai tertinggi dan sebaliknya saya merasa gagal jika nilai saya lebih rendah dari teman-teman sekelas didapat rata-rata skor $(3,48)$ artinya berada pada kategori sangat baik.

Dari tabel di atas diketahui bahwa banyak siswa yang menjawab selalu (7), sering (13), kadang-kadang (4) dan tidak pernah (1). Analisa pada angketSaya akan mengulang-ulang pelajaran yang sudah agar faham tujuan dari pelajaran tersebut didapat rata-rata skor $(3,04)$ artinya berada pada kategori baik. 
Tabel 27Saya akan menerapkan nilai-nilai yang terkandung pelajaran terserbut pada kehidupan saya

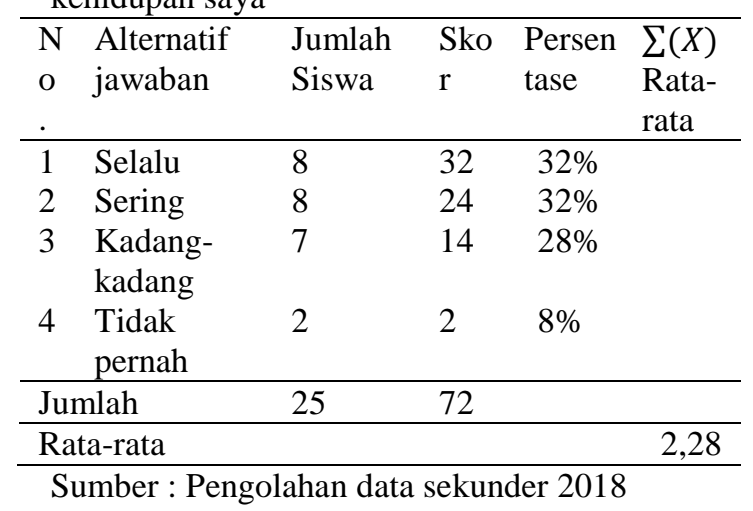

Dari tabel di atas diketahui bahwa banyak siswa yang menjawab selalu (8), sering (8), kadang-kadang (7), dan tidak pernah (2). Analisa pada angket Saaya suka kelar rumah pada malam harididapat rata-rata skor $(2,28)$ artinya berada pada kategori kurang baik.

Selanjutnya untuk

membuktikan penelitian yang dikemukakan dilakukan dengan menggunakan koefisien korelasi. Teknik koefisien korelasi maksudnya adalah suatu teknik untuk melihat hubungan satu variabel dengan variabel lainnya, yaitu variabel $\mathrm{x}$ (motivasi siswa) dan variabel y (prestasi siswa). Maka dari itu terlebih dahulu dibuat analisis jawaban responden tentang hubungan pergaulan terhadap prestasi siswa SMPN 2 Kecamatan Situjuah Limo Nagari Kabupaten Limapuluh Kota. Berikut adalah table koefisien korelasi hubungan motivasi siswa terhadap prestasi siswa SMPN 2 Kecamatan Situjuah Limo Nagari Kabupaten Limapuluh Kota :

$$
\begin{gathered}
\mathrm{r}_{\mathrm{xy}}=\frac{\square \sum \square \square-\left(\sum \square\right)\left(\sum \square\right)}{\sqrt{\left(\square \sum \square^{2}\right.}-\left(\sum \square\right)^{2} \square \sum \square^{2}-\left(\sum \square\right)^{2}} \\
\frac{\mathrm{r}_{\mathrm{xy}}}{\sqrt{\left[(25 \square 171671)-(2.049)^{2}\right]\left[(25 \square 334494)-(1888)^{2}\right]}}
\end{gathered}
$$

$$
\begin{aligned}
&= \\
& \frac{4025775-3870300}{\sqrt{[(4291775-4198401)][(8362373.35-356643)]}} \\
&=\frac{155475}{\sqrt{(93374)(8005730.35)}} \\
&=\frac{155475}{\sqrt{747527065999}} \\
&=\frac{155475}{86459.6475} \\
& \mathbf{r}=\mathbf{0 , 5 6 6 1}
\end{aligned}
$$

\section{Uji Hipotesis}

$$
\begin{aligned}
\mathrm{t} & =\frac{\square \sqrt{\square-2}}{\sqrt{1-\square^{2}}} \\
& =\frac{0,56613 \sqrt{25-2}}{\sqrt{1-(0,5661)^{2}}} \\
& =\frac{0,5661 \sqrt{23}}{\sqrt{1-0,3204}} \\
& =\frac{(0,5661)(4,7)}{\sqrt{0,6796}} \\
& =\frac{266067}{0,8243}
\end{aligned}
$$

$\mathbf{t}=\mathbf{3 . 2 2 7 7}$

Setelah diperoleh t dari rumus tersebut, dilanjutkan dengan membandingkan nilai $t_{\text {hitung }}$ dengan

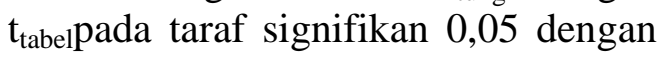
derajat kebebasan $\mathrm{n}-2(25-2)$. Untuk lebih jelasnya dapat dilihat tabel berikut ini:

Tabel 28 Uji Hipotesis Pergaulan

\begin{tabular}{lccl}
\hline $\mathrm{R}$ & $\mathrm{T}_{\text {hitung }}$ & $\mathrm{N}-2$ & $\begin{array}{l}\mathrm{T}_{\text {tabel }} \\
\mathrm{P} 0,05\end{array}$ \\
\hline 0,5661 & 3.2277 & 23 & 1,7138 \\
\hline
\end{tabular}

Pengujian

hipotesis berdasarkan $r_{\text {hitung }}$ 0,3663 diperoleh $\mathrm{t}_{\text {hitung }} 1,8510$ dengan derajat kebebasan $\mathrm{N}-2(25-2=23)$, dan taraf signifikan 0,05 . Hipotesis diterima jika $t_{\text {hitung }}>$ $t_{\text {tabel }}$. Dengan demikian $\mathrm{H}_{1}$ diterima karena hasil pengjian membuktikan bahwa $t_{\text {hitung }}$ lebih besar dari $t_{\text {tabel }}$ yaitu $3.2277>1,7138$. Dapat disimpulkan bahwa terdapat hubungan yang sangat signifikan antara motivasi dengan prestasi belajar siswa kelas VIII SMPN 2 Kecamatan Situjuah Limo Nagari Kabupaten Lima Puluh Kota. 
Menurut Sardiman A.M, (2007:75) Motivasi adalah seluruh daya penggerak di dalam diri siswa yang menimbulkan kegiatan belajar yang menjamin kelangsungan dari kegiatan belajar yang memberikan arah pada kegiatan belajar sehingga tujuan yang di kehendaki oleh subjek belajar itu dapat dicapai.

Tetapi dari hasil pengamatan penulis di lapangan memang kurang motivsai siswa dalam belajar yang berimbas pada prestasi siswa terserbut semua itu di sebabkan banyak hal tapi konteksnya di pengaruhi oleh Lingkungan Sekolah, Lingkungan Msyarakat, Dan Lingkungan Keluarga dan dari hasill angket yang di dapat bahwasanya tinggi mottivasi di kelas 8 SMPN 2 Kec.Situjuah Limo Nagari terbilang cukup baik di karena kan rata-rata nilai yang di dapatkan dari angket motivasi siswa yaitu 82 yang berada pada kualifikasi baik. Berdasarkan tabel analisis data dapat disimpulkan bahwa kualifikasi baik sekali diperoleh 7 orang dengan persentase $10,00 \%$, kualifikasi baik diperoleh 7 orang dengan persentase $35,00 \%$, kualifikasi lebih dari cukup diperoleh 8 orang dengan persentase $40 \%$, kualifikasi cukup dan diperoleh 3 orang dengan persentase $15,00 \%$. Dapat di lihat pada tabel 4.28 bahwasanya motivasi belajar siswa dalam keadaan baik.

Tabel 29 Hasil rata-rata dari rekapitulasi angket motivasi siswa

\begin{tabular}{llll}
\hline No & Jenis Pertanyaan & $\begin{array}{l}\text { Rata- } \\
\text { rata } \\
\text { skor }\end{array}$ & Kategori \\
\hline 1 & $\begin{array}{l}\text { Saya } \\
\text { memperhatikan } \\
\text { dengan sungguh- } \\
\text { sungguh materi } \\
\text { yang di sampaikan } \\
\text { oleh guru }\end{array}$ & $\begin{array}{l}\text { Sangat } \\
\text { Baik }\end{array}$ \\
\hline 2 & $\begin{array}{l}\text { Saya bersemangat } \\
\text { mengerjakan tugas } \\
\text { yang diberikan guru }\end{array}$ & \\
\hline 3 & Saya $\quad$ senang & \\
\hline
\end{tabular}

\begin{tabular}{|c|c|c|c|}
\hline & $\begin{array}{l}\text { mendapatkan pujian } \\
\text { ketika mendapat } \\
\text { nilai bagus }\end{array}$ & & Baik \\
\hline 4 & $\begin{array}{lr}\begin{array}{l}\text { Saya masuk } \\
\text { sebelum }\end{array} & \text { kelas } \\
\text { berbunyi } & \text { bel } \\
\end{array}$ & 3,36 & $\begin{array}{l}\text { Sangat } \\
\text { Baik }\end{array}$ \\
\hline 5 & $\begin{array}{l}\text { Saya berusaha tepat } \\
\text { waktu } \\
\text { mengumpulkan } \\
\text { latihan dan } \\
\text { pekerjaan rumah }\end{array}$ & 3,24 & Baik \\
\hline 6 & $\begin{array}{l}\text { Memanfaatkan } \\
\text { waktu yang ada } \\
\text { untuk } \\
\text { menyelesaiakan } \\
\text { tugas dan latihan } \\
\text { yang diberikan }\end{array}$ & 3,20 & Baik \\
\hline 7 & $\begin{array}{lr}\text { Sarapan } & \text { sebelum } \\
\text { berangkat } & \text { ke } \\
\text { sekolah } & \\
\end{array}$ & 2,44 & $\begin{array}{l}\text { Kurang } \\
\text { Baik }\end{array}$ \\
\hline 8 & $\begin{array}{l}\text { Membawa bekal } \\
\text { untuk menghemat } \\
\text { uang jajan agar bisa } \\
\text { menabung }\end{array}$ & 1,84 & $\begin{array}{l}\text { Kurang } \\
\text { Baik }\end{array}$ \\
\hline 9 & $\begin{array}{l}\text { Ketika jam istirahat } \\
\text { saya selalu makan } \\
\text { dan } \\
\text { secukupnya }\end{array}$ & 4,32 & $\begin{array}{l}\text { Sangat } \\
\text { Baik }\end{array}$ \\
\hline 10 & $\begin{array}{l}\text { Lebih mudah } \\
\text { memahami materi } \\
\text { jika dihubungkan } \\
\text { dengan kehidupan } \\
\text { sehari-hari }\end{array}$ & 3,32 & $\begin{array}{l}\text { Sangat } \\
\text { Baik }\end{array}$ \\
\hline 11 & $\begin{array}{l}\text { Saya merasa bosan } \\
\text { jika guru selalu } \\
\text { berceramah } \\
\text { menyuruh mengisi } \\
\text { LKS (-) }\end{array}$ & 2,80 & Baik \\
\hline 12 & $\begin{array}{l}\text { Saya senang jika } \\
\text { penyampaian } \\
\text { materi } \\
\text { menggunakan } \\
\text { media }\end{array}$ & 3,12 & Baik \\
\hline 13 & $\begin{array}{l}\text { Saya lebih suka } \\
\text { mencatat daripada } \\
\text { mendengarkan apa } \\
\text { yang disampaikan } \\
\text { guru (-) }\end{array}$ & 2,24 & $\begin{array}{l}\text { Kurang } \\
\text { Baik }\end{array}$ \\
\hline 14 & $\begin{array}{lr}\text { Saya } & \text { senang } \\
\text { berdikusi } & \text { dengan } \\
\text { teman tentang apa } \\
\text { yang } & \text { sudah } \\
\text { dipelajari } & \\
\end{array}$ & 3,20 & Baik \\
\hline 15 & $\begin{array}{lr}\text { Belajar } & \text { bersama } \\
\text { dengan } & \text { teman- } \\
\text { teman } & \text { untuk }\end{array}$ & 2,68 & Baik \\
\hline
\end{tabular}




\begin{tabular}{|c|c|c|c|}
\hline & $\begin{array}{l}\text { mengerjakan tugas } \\
\text { atau PR yang sulit(- } \\
\text { ) }\end{array}$ & & \\
\hline 16 & $\begin{array}{lr}\text { Saya senang } \\
\text { membantu teman } \\
\text { yang kesulitan } \\
\text { dalam belajar }\end{array}$ & 3,08 & Baik \\
\hline 17 & $\begin{array}{lr}\text { Saya senang jika } \\
\text { pekerjaan rumah } \\
\text { selalu di } & \text { koreksi } \\
\text { oleh } & \text { orang } \\
\text { tua/saudara } & \\
\end{array}$ & 2.48 & $\begin{array}{l}\text { Kurang } \\
\text { Baik }\end{array}$ \\
\hline 18 & $\begin{array}{lr}\text { Saya memilih di } \\
\text { antar oleh orang } \\
\text { tua/saudara } \\
\text { sekolah dan jemput } \\
\text { ketika } \\
\text { sekolah }\end{array}$ & 2,04 & $\begin{array}{l}\text { Kurang } \\
\text { Baik }\end{array}$ \\
\hline 19 & $\begin{array}{lr}\text { Pujian dari } & \text { orang } \\
\text { tua/saudara } & \text { selalu } \\
\text { membuat } & \text { saya } \\
\text { bersemanggat } & \\
\end{array}$ & 3,60 & $\begin{array}{l}\text { Sangat } \\
\text { Baik }\end{array}$ \\
\hline 20 & $\begin{array}{lr}\begin{array}{l}\text { Saya } \\
\text { bertanya }\end{array} \text { kelalu } \\
\text { orang tua/saudara } \\
\text { jika ada yang saya } \\
\text { tidak mengerti dari } \\
\text { pelajaran disekolah } \\
\begin{array}{l}\text { dan pekerjaan } \\
\text { rumah }\end{array} \\
\end{array}$ & 3,16 & Baik \\
\hline 21 & $\begin{array}{l}\text { Saya senang } \\
\text { mendapatkan nilai } \\
\text { tinggi dalam setiap } \\
\text { latihan dan } \\
\text { pekerjaan rumah }\end{array}$ & 3,64 & $\begin{array}{l}\text { Sangat } \\
\text { Baik }\end{array}$ \\
\hline 22 & $\begin{array}{l}\text { Saya berusaha } \\
\text { mendapatkan nilai } \\
\text { tinggi }\end{array}$ & 3,64 & $\begin{array}{l}\text { Sangat } \\
\text { Baik }\end{array}$ \\
\hline 23 & \begin{tabular}{ll}
\multicolumn{3}{l}{ Tinggi/rendahnya } \\
nilai yang saya \\
dapatkan akan \\
\multicolumn{2}{c}{ selalu saya syukuri } \\
\end{tabular} & 3,68 & $\begin{array}{l}\text { Sangat } \\
\text { Baik }\end{array}$ \\
\hline 24 & \begin{tabular}{lr} 
Saya merasa \\
berhasil jika \\
mendapatkan & nilai \\
tertinggi & dan \\
sebaliknya & saya \\
merasa gagal jika \\
nilai saya lebih \\
rendah dari teman- \\
\multicolumn{2}{l}{ teman sekelas } \\
\end{tabular} & 3,48 & $\begin{array}{l}\text { Sangat } \\
\text { Baik }\end{array}$ \\
\hline 25 & $\begin{array}{l}\text { Saya akan berusaha } \\
\text { memahami setiap } \\
\text { apa yang sudah di } \\
\text { pelajari dan akan } \\
\text { terus mengingatnya }\end{array}$ & 3,08 & Baik \\
\hline
\end{tabular}

\begin{tabular}{|c|c|c|c|}
\hline 26 & $\begin{array}{lc}\text { Saya } & \text { akan } \\
\text { mengulang-ulang } \\
\text { pelajaran y yang } \\
\text { sudah agar faham } \\
\text { tujuan dari } \\
\text { pelajaran tersebut }\end{array}$ & 3,04 & Baik \\
\hline 27 & $\begin{array}{lr}\begin{array}{l}\text { Saya } \\
\text { menerapkan }\end{array} & \text { akan } \\
\text { nilai- } & \text { yang } \\
\text { terkandung } & \\
\text { pelajaran tersebut } \\
\text { pada kehidupan } \\
\text { saya }\end{array}$ & 2,28 & $\begin{array}{l}\text { Kurang } \\
\text { Baik }\end{array}$ \\
\hline
\end{tabular}

Prestasi belajar merupakan hasil pengukuran terhadap peserta didik setelah mengikuti proses pembelajaran dalam periode tertentu yang dapat diukur menggunakan instrumen yang relevan.Berdasarkan hasil analisis data, menunjukkan bahwa rata-rata nilai hasil belajar siswa yaitu 78 yang berada pada kualifikasi baik. Berdasarkan tabel analisis data dapat disimpulkan bahwa kualifikasi baik sekali diperoleh 9 orang dengan persentase $10,00 \%$, kualifikasi baik diperoleh 7 orang dengan persentase $65,00 \%$, kualifikasi lebih dari cukup diperoleh 9 orang dengan persentase $25.00 \%$.

Hasil Observasi selama penelitian yang penulis dapatkan yaitu selama penyebaran angket siswa dan siswi kurang memerhatikan dan cenderung asal-asalan dalam pengisian angket bahkan ada yang mencontek kepada teman. Karna selama Penelitian penulis mungkin dianggap sebagai orang baru dan tidak mendapatkan perhatian dari siswasiswi tersebut. Kelancaran penyebaran angket di dalam kelas tersebut di karenakan penulis di dampinggi oleh guru mata pelajaran selama waktu yang penulis butuhkan selama penelitian di dalam kelas. 


\section{SIMPULAN}

Berdasarkan keseluruhan item soal didapat rata-rata secara keseluruhan yaitu 3,31. Ini berarti pada kategori baik. Dapat diartikan bahwa motivasi belajar siswa sudah berjalan dengan baik seperti yang di harapkan. Dari hasil uji hipotesis dan pengolahan data terdapat hubungan antara motivasi belajar dengan prestasi belajar siswa sehingga diperoleh harga koefinsien korelasi antara $\mathrm{X}$ dan $\mathrm{Y}$ sebesar 0,56 berarti dalam kategori sedang.

\section{DAFTAR PUSTAKA}

A.M. Sardiman. (2007). Interaksi dan Motivasi Belajar Mengajar. Bandung: Rajawali Pers

Djamarah, S., B. (2008). Psikologi Belajar. Jakarta: Rineka Cipta

Sugiyono. (2010). Metode Pendidikan Pendekatan Kuantitatif, Kualitatif, dan R\&D. Bandung: Alfabeta

Agustina, L. (2011). Pengaruh Motivasi Belajar Siswa Terhadap Prestasi Belajar IPA di Sekolah. Jurnal Penelitian, 1 (2) 